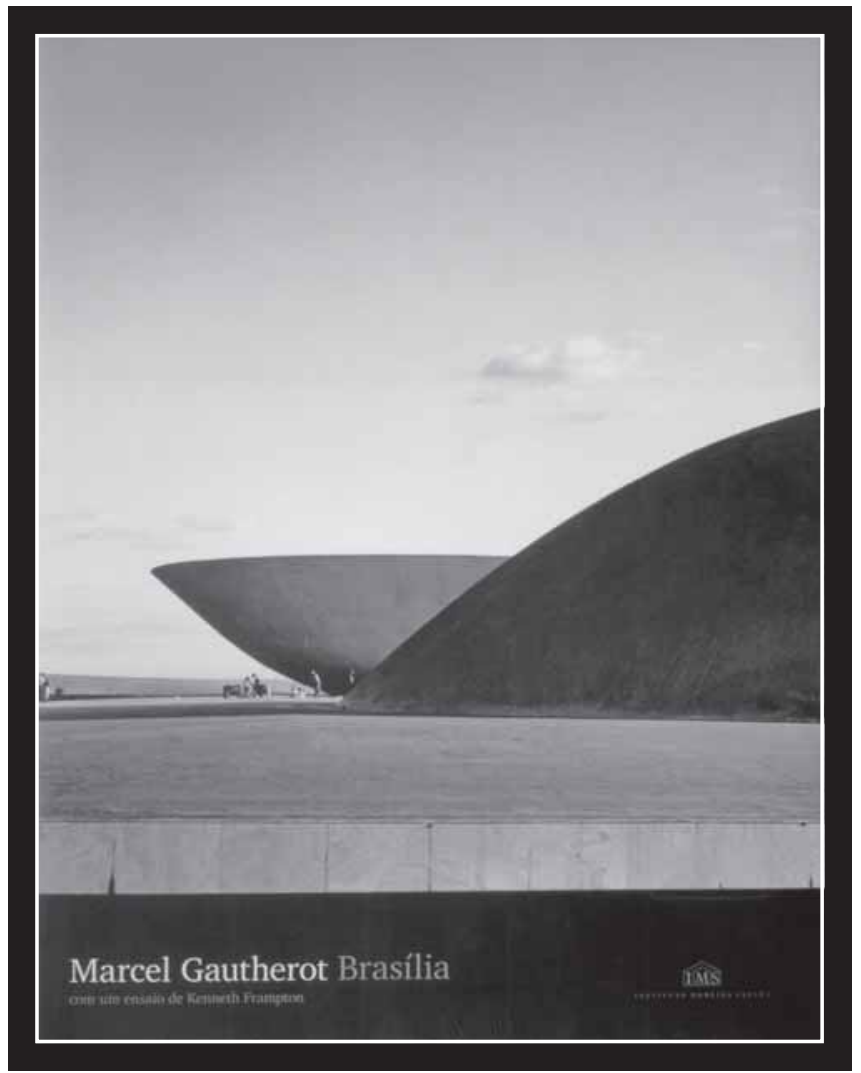

Marcel Gautherot Brasília, organizado por Sergio Burgi e Samuel Titan Jr. São Paulo: Instituto Moreira Salles, 2010. 192 p. 


\title{
O encontro entre fotografia e arquitetura em Marcel Gautherot Brasília
}

\author{
Mariana FerreiraLopes*
}

O ano de 2010 foi marcado pelas comemorações do aniversário de cinquenta anos de Brasília, um marco arquitetônico e histórico para o Brasil. Sua construção foi fruto de um sonho compartilhado por mentes inquietas que a imaginaram e a delinearam em meio à vastidão inexplorada do Planalto Central e executada por trabalhadores vindos de todas as regiões, cuja esperança transformou a poeira do cerrado intocado em um cenário de obras monumentais. Nas palavras de seu idealizador, o expresidente Juscelino Kubitschek (2000, p.23):

De fato, o cenário de Brasília tem aspectos realmente singulares. As cúpulas do Palácio do Congresso - uma côncava e uma convexa; a imponência da Praça dos Três Poderes, refletindo o brilho de suas sucessivas fachadas de vidro; o Palácio do Supremo Tribunal da Justiça, apoiado em alicerces tão tênues que dão a impressão de que o edifício não toca o chão, mas flutua; a beleza do Palácio da Alvorada, concebido em linhas de uma harmonia tão perfeita, que o traçado de suas colunas sui generis já é motivo ornamental até de certo tipo de louça sofisticada - tudo ali é diferente. Revolucionário. Reflete uma estética urbanística única no mundo.

A epopeia da construção da nova capital federal no fim da década de 50 criou um alvoroço no país, dividindo opiniões entre os que acreditavam na proposta de JK e os que achavam que não passava de um devaneio que prejudicaria o Brasil. No centro das discussões políticas nacionais, a empreitada foi pauta constante nos periódicos da época atraindo jornalistas e fotógrafos do mundo todo em busca de um registro

* Jornalista. Mestranda em Comunicação pela Universidade Estadual de Londrina (UEL). Bolsista da Capes - Coordenação de Aperfeiçoamento do Pessoal de Nível Superior. 
desta saga. Um desses personagens foi o francês Marcel Gautherot que, apesar de não ser o fotógrafo oficial do governo - cargo exercido por Mário Fontenelle-, foi convidado por Oscar Niemeyer para capturar em suas lentes o desabrochar da nova cidade.

O resultado de cerca de dois anos de viagens constantes ao Planalto Central consiste em um material vasto formado por três mil imagens tiradas, em sua maioria, com câmeras Rolleiflex e Hasselblad, em pretoe-branco - que revelam tanto a essência da grandiosidade e da audácia arquitetônica e urbanística de Brasília como o cotidiano dos trabalhadores que a ergueram, os chamados candangos.

Devido às celebrações simultâneas do cinquentenário de Brasília e do centenário de nascimento de Marcel Gautherot, o Instituto Moreira Salles (IMS), que reúne e preserva as imagens do fotógrafo francobrasileiro, lançou em abril de 2010 o livro Marcel Gautherot Brasília. A obra foi organizada por Sergio Burgi, coordenador de Fotografia e Reserva Técnica Fotográfica do IMS, e por Samuel Titan Jr., professor doutor do Departamento de Teoria Literária da Universidade de São Paulo, e apresenta 153 imagens sobre cada passo da construção da capital federal.

O livro, dividido em cinco partes, apresenta um texto introdutório de Burgi sobre a relação entre fotografia etnográfica e arquitetura na práxis fotográfica de Marcel Gautherot; o ensaio do arquiteto britânico e professor da Universidade de Columbia em Nova Iorque, Kenneth Frampton, sobre a arquitetura e o planejamento urbano de Brasília; o portfólio de Gautherot, ilustrado por depoimentos de Niemeyer, escritos de Lucio Costa e trechos do periódico Brasília; uma biografia do fotógrafo, redigida por Titan Jr.; e a cronologia de Brasília, por Maria Beatriz Cappello.

Trata-se de um livro inédito sobre o tema visando não apenas contemplar os leitores com um rol de fotografias da construção de Brasília, mas demonstrar como este trabalho fotográfico pôde ser realizado tendo em vista as particularidades da formação de seu criador, que influenciaram na captura de suas imagens e expõem a sua qualidade estética. O livro 
traz elementos de seus dois fios condutores, Marcel Gautherot e Brasília, ao mostrar como o estilo do fotógrafo encontrou na edificação desta cidade seu cenário ideal.

Titan Jr., ao contar a trajetória pessoal e profissional de Marcel Gautherot, elucida como foram moldados o pensamento e a estética do fotógrafo que atingem uma notável maturidade nas imagens de Brasília. Nascido em Paris em 1910, aos 15 anos Gautherot iniciou seus estudos sobre arquitetura na École Nationale des Arts Décoratifs que perduraram até 1931, antes de ser chamado para prestar o serviço militar obrigatório. Durante sua formação acadêmica incompleta, a arquitetura foi marcada pela ascensão da vertente modernista centrada no pensamento de Le Corbusier e da Escola de Bauhaus, pressupostos que marcaram a sua estética. $\mathrm{O}$ interesse pela fotografia surgiu em meados da década de 30, quando participou da Alliance Photo e trabalhou no Museu do Homem, atuando em projetos arquitetônicos e fotográficos. Segundo Titan Jr, Gautherot trabalhou com Pierre Verger nas coleções etnográficas do museu. Em 1936, viajou pela instituição francesa ao México a fim de realizar um registro de monumentos pré-colombianos.

Atuando como fotógrafo etnográfico, Gautherot realizou seu desejo de viajar e conhecer outras culturas. Por conta deste ensejo, após ler o romance Jubiabá, de Jorge Amado, planejou uma viagem ao Brasil. Em 1939, desembarcou em Recife, onde ficou pouco tempo, pois foi convocado pelo exército francês para atuar na Segunda Guerra Mundial. Retornou ao Brasil no mesmo ano, fixando residência no Rio de Janeiro e estabelecendo relações com importantes nomes da arte brasileira. Trabalhou por mais de três décadas no Serviço do Patrimônio Histórico e Artístico Nacional (SPHAN), o que o aproximou de Oscar Niemeyer e do círculo de arquitetos modernistas. Titan Jr. (2010, p.182) conta que "com Niemeyer, as afinidades são pessoais, estéticas e também políticas. A contar do conjunto da Pampulha, em Belo Horizonte, até meados da década de 70, Gautherot fotografaria todos os projetos importantes que o amigo realizou no Brasil”. Inclusive Brasília, registrada em todas as suas fases de construção pelas lentes 
do fotógrafo e em visitas posteriores, quando fotografou a cidade para o governo e para a documentação das obras de Niemeyer.

Além da arquitetura, as lentes de Marcel Gautherot capturaram também a expressão da diversidade cultural brasileira na campanha de preservação do folclore nacional, a partir de seu olhar de fotógrafo etnográfico, e as obras paisagísticas de seu amigo Burle Marx. Em 1986, o foco de seu trabalho esteve em organizar seu arquivo fotográfico. Gautherot faleceu em 8 de outubro de 1996.

Brasília, por sua vez, é apresentada por Kenneth Frampton em seu ensaio $O$ destino de Brasília como uma cidade inigualável se comparada a qualquer capital que tenha sido erguida após os meados do século XX. Esta áurea deriva das características do cenário político e cultural do processo de modernização brasileira, ao qual Frampton salienta a expressividade de uma linguagem própria nos campos da arte e da arquitetura a partir de nomes como Villanova Artigas, Oscar Niemeyer, Burle Marx e Cândido Portinari.

Na criação de Brasília prevalecem elementos que ressaltam as suas peculiaridades tais como a rapidez de sua construção - cerca de dois anos - e o caráter monumental de seu planejamento urbanístico e de seu projeto arquitetônico, cujas essências foram capturadas por Gautherot. Frampton (2010, p.19) lembra "que Brasília tenha sido realizada na crista de uma onda histórica tão promissora é comoventemente evocado pelas fotografias elegíacas do francês Marcel Gautherot” (2010, p.19). Ele ainda esmiúça para os leitores os elementos constitutivos das matrizes do urbanismo brasiliense ressaltando o conceito de Superquadras e a concepção dos eixos do Plano Piloto, ambos concebidos por Lucio Costa.

Neste sentido, Burgi entende que o cenário da construção de Brasília consistiu em uma oportunidade única para Gautherot exprimir a articulação entre suas duas áreas de formação: a arquitetura e a fotografia. Em seu texto Fotografia e arquitetura: Marcel Gautherot em Brasília, ele explica que a luz se apresenta como o elemento fundamental 
tanto para a uma quanto para a outra, sendo este o pressuposto que leva Gautherot a afirmar que fotografia é arquitetura e somente alguém que conhecesse arquitetura seria capaz de capturar uma boa imagem. Para Burgi, a fotografia do Congresso Nacional ao por-do-sol, que compõe o portfólio do livro, é a síntese da unidade buscada pelo fotógrafo franco-brasileiro em suas imagens. Gautherot buscou capturar o desenho arquitetônico da obra em questão que,

[...] só se evidencia por inteiro graças à dupla capacidade, apurada por Gautherot, de aguardar a melhor incidência e intensidade de luz e de controlar precisamente a exposição da película fotográfica, o que garante o registro em definição ótima das infinitas gradações de luz em interação com as superfícies construídas - desenhando, recobrindo, refletindo todas as nuances dos volumes, planos e texturas da edificação. (BURGI, 2010, p.14-15).

Esta convergência estética pode ser observada nas fotografias no portfólio ou nas ilustrações dos ensaios, notas e textos, que registram a construção da Esplanada dos Ministérios, da Catedral Metropolitana Nossa Senhora Aparecida, dos Palácios da Alvorada e Itamaraty, da Praça dos Três Poderes e do Congresso Nacional. São imagens que revelam os detalhes e a monumentalidade que Brasília reverbera a partir do trabalho articulado de elementos como a luz, a volumetria das obras e os imensos espaços vazios sendo rapidamente ocupados.

Mas não foi apenas a arquitetura que as lentes de Gautherot capturaram em Brasília. Em boa parte das imagens - ou em fotografias específicas nas quais o caráter etnográfico de sua formação emerge encontra-se o elemento humano, registrado em seu cotidiano, nos canteiros de obras ou em suas casas, desnudando a face dos candangos que ergueram a cidade lado a lado com os homens que a imaginaram. No portfólio, dividem o mesmo espaço as imagens da realidade dos trabalhadores situada no improviso das cidades satélites e a construção planejada e estonteante de Brasília, assim como fotografias de simples trabalhadores e da figura mítica de Juscelino Kubistchek. 
Marcel Gautherot Brasília apresenta um recorte de 153 fotografias das três mil realizadas pelo fotógrafo no registro da construção de Brasília e em visitas posteriores à cidade. As imagens e textos que compõem o livro traduzem o cruzamento das trajetórias de Gautherot e Brasília, revelam para o leitor o potencial na relação entre fotografia e arquitetura e, mais, exprimem o resultado do encontro entre a formação de um fotógrafo e o cenário ideal para a execução de sua obra. Na conclusão de Burgi (2010, p.9), “em Brasília, todos os elementos da formação estética e do olhar fotográfico de Gautherot puderam convergir”.

\section{Referência}

KUBISTCHEK, Juscelino. Por que construí Brasília. Brasília:

Senado Federal, 2000. 